\title{
Investigating economic growth-energy consumption-environmental degradation nexus in China
}

\author{
Siok Kun Sek*, Jenq Fei Chu \\ School of Mathematical Sciences, Universiti Sains Malaysia, 11800 Minden, Penang, Malaysia
}

\section{A RT ICLE INFO}

\section{Article history:}

Received 7 March 2017

Received in revised form

4 October 2017

Accepted 8 October 2017

\section{Keywords:}

Energy consumption

Economic growth (GDP)

Environmental degradation

Environmental Kuznets curve (EKC)

\begin{abstract}
A B S T R A C T
The impact of energy consumption and its relationship with macroeconomic variables is always the concern of policy authorities. In this paper, we conduct empirical analyses on testing the inter-relationship between energy consumption with economic growth (GDP) and environmental degradation (greenhouse gases emissions). Our main objective is to indicate the direction of causal (uni-directional or bi-directional) relationship on these variables and the dynamic of the relationship (symmetric or asymmetric and permanent or temporary). The Granger causality tests and cointegration tests (linear versus threshold) are applied. Our results reveal bi-directional relation between energy consumption and greenhouse gases emissions and uni-directional causal effect from GDP to energy consumption in the shortrun. Our threshold cointegration test reveals long-run asymmetric causal effect from energy consumption and greenhouse gases emissions to GDP while the linear cointegration tests detect symmetric long-run relationship in the model with energy consumption and greenhouse gases emissions as dependent variable respectively.
\end{abstract}

(C) 2017 The Authors. Published by IASE. This is an open access article under the CC BY-NC-ND license (http://creativecommons.org/licenses/by-nc-nd/4.0/).

\section{Introduction}

Energy resources are important sources in our daily life either for household consumption or for industrial production purposes. The sectors that are highly energy dependence such as transportation, chemical and electronic consume energy resources intensively. Also, countries that are highly dependent on energy are the main energy importing countries as energy resources are the engines for productions/ industrialized activities which foster economic development. While energy consumption may lead to positive outcome in terms of economic growth, it is unavoidable comes with a trade-off cost in terms of environment degradation. In turn, there might be bi-directional causal effect among energy consumption, economic growth and environmental degradation (greenhouse gases emissions) which determine the trend and the outcome of these variables that may impact the economy at national and at globally levels.

The investigation on energy consumption, economic growth and environmental degradation

\footnotetext{
* Corresponding Author.

Email Address: sksek@usm.my (S. K. Sek)

https://doi.org/10.21833/ijaas.2017.012.005

2313-626X/C) 2017 The Authors. Published by IASE.

This is an open access article under the CC BY-NC-ND license

(http://creativecommons.org/licenses/by-nc-nd/4.0/)
}

has long been conducted. Yet this topic remains important and permits further exploration as previous studies reported no consensus on the relationship. Further investigation may reveal important information on the interaction of each variable to the other (one-way or two-way relation) and the dynamic behaviour on the relationship (symmetric versus asymmetric, permanent or temporary) which provides guidelines/ recommendations for the policymaker in effective policy decision and economic planning, taking into consideration on the environmental issues and energy conservation for sustainable growth.

This research topic is especially important for the countries that highly energy intensive like China. China is the second largest economy in the world after U.S. showing high growing rate of $10 \%$ between 1980 and 2009. However, the growing progress came with the cost of environmental degradation. In 2007, the World Bank approximated that the air and water pollution caused to the loss of roughly US $\$ 100$ billion per year or $5.8 \%$ of GDP in China. Realizing the importance to gain balancing between industrialization and environmental quality, China is looking forward 'harmonious society' with slower GDP growth and less environmental degradation problem. The economy policy has shifted from heavy industry and export production to focusing on domestic consumption and demand (Leggett, 2011). 
Also, China has integrated the climate action into its 13th Five Year Plan. According to the IEA estimates in year 2005, China is the largest emitter of greenhouse gases and carbon dioxide. According to the estimates of BP, the carbon dioxide emissions in China grew 339\% between 1990 to 2010. China has committed to the international climate policies and obligations. For instance, China has targeted to achieve $40-45 \%$ reduction in carbon intensity by year 2020 under the 2009 Copenhagen Accord, obliged to the 1997 Kyoto Protocol to reduce greenhouse gases emissions (Leggett, 2011).

In this paper, we focus the investigation on the relationship among energy consumption, GDP and greenhouse gases emissions for China since China is the main oil importing country and the largest greenhouse and $\mathrm{CO} 2$ gases emitting country based on the 2013 record of International Energy Agency. We are interested to investigate the dynamic relationship on these three variables in the highly energy intensive country of China. Applying the Granger causality test, our results reveal bidirectional relationship between energy consumption and greenhouse gases emissions and a one-way causal effect from GDP to energy consumption in the short-run. Applying linear and threshold cointegration tests, we find evidences on the long-run (permanent) relationship among the three variables. The asymmetric long-run relation exist in the model with GDP as dependent variable while symmetric long-run relation appear in the model with energy consumption and greenhouse gases emissions as dependent variable respectively.

The remaining paper is organized as follows: section 2 provides reviews on background study and findings; section 3 explains the data and methodology applied; section 4 discusses the results and section 5 concludes the findings.

\section{Literature review}

The relationship among energy consumption, economic growth and environmental degradation (carbon dioxide and other greenhouse gases emissions) have attracted continuously researches using different methods and applied different countries and time periods. Among these studies, a number of researches focused on the relationship between GDP and environmental degradation. Grossman and Krueger $(1991,1995)$ proposed the environmental Kuznets curve (EKC) to hypothesize the relationship between the level of the environmental degradation and income growth. Such relationship is represented by an inverted-U curve where higher income is associated with higher environmental deterioration which is peaked at a turning point and after this point higher income leads to lower environmental deterioration. They claimed that the turning point is reached when higher income gain together with improved air quality as proxy for the environmental variable. Since then, EKC hypothesis were studied extensively. A number of studies reveal the validity of EKC
inverted-U curve such as Al Sayed et al. (2013), Wang (2013), Galeotti and Lanza (1999) and Franklin and Ruth (2012) while many studies reported other shapes that deviated from the EKC hypothesis. For instance, the detection of N-shape was reported in Balin and Akan (2015). Among other studies detected deviations from EKC hypothesis include Esteve and Tamarit (2012), Huang et al. (2008) and Tsurumi and Managi (2010).

Apart from the relationship between GDP and environmental quality, a broad research has been conducted on the impact of energy consumption on growth and environmental quality with a broad study focused on energy consumption-growth nexus. Kraft and Kraft (1978) was the first to study the relationship between energy consumption and economic growth in U.S. Since then, many studies were conducted on this topic but these studies reported very different results. Ozturk (2010) and Payne (2010) provided a literature survey on the nexus of energy-growth. According to Ozturk (2010), there is no conclusion reached on the causal relationship between the two variables. However, majority studies revealed different types of causality results and the conflicting results may due to factors such as time periods, variables used, methodologies applied and countries' characteristics. The investigation on the energy consumption-economic growth nexus leads to two opposite views. The first view is termed as 'neutrality hypothesis' which suggests neutrality impact from energy consumption to growth. The second view suggests limiting effect from energy consumption to growth depending on economic structure and the exact growth stage of a country. When the economy is growing, its production structure tends to shift toward services sector which is not energy intensive. This leads to inconclusive results on the existence effect and direction of causality between economic growth and energy consumption (Alshehry and Belloumi, 2015).

Ozturk (2010) categorized the directions of causal relationship into four types: (1) no causality or referred as 'neutrality hypotheses; (2) unidirectional causality effect from economic growth to energy consumption which termed as 'conservation hypotheses. This hypothesis is supported when the increase in real GDP leads to higher energy consumption; (3) uni-directional causality effect from energy consumption to economic growth which called 'growth hypothesis', higher energy consumption may stimulate higher growth directly and indirectly through production process; (4) bidirectional causality or the 'feedback hypothesis', both energy consumption and economic growth have causal effect on each other. The studies reported no causality evidence on the nexus include Fatai et al. (2002), Halicioglu (2009) and Soytas and Sari (2009). The studies revealed type (2) results include Ang (2008), Ghosh (2002) and Narayan and Smyth (2005). Results supported type (3) hypothesis include $\mathrm{Hu}$ and Lin (2008) and Yuan et al. (2008) while results supported for type (4) hypothesis 
include Odhiambo (2009), Yoo (2005) and Apergis and Payne (2009).

A number of studies include carbon dioxide emissions (or other greenhouse gases emissions) in the energy consumption-economic growth nexus and majority studies found causal relationship on these three variables. Among these studies include Soytas and Sari (2009), Wolde (2016), Alege et al. (2016) and Chindo et al. (2015).

\section{Data and methodology}

The study is focused on China. The three variables used in the analyses include greenhouse gases emissions (kt) (GREEN) as a proxy for environmental degradation, gross domestic product (current US\$) (GDP) as a proxy for income level and primary energy consumption (millions tons of oil equivalent) (EC) is used to proxy for total energy consumed. The data are in annually format which are extracted from the Datastream and World Bank for the periods of 1970-2012. All data are transformed into log form for consistency.

In analysing the inter-relationship among these three variables, the possible models include (Eqs. 13):

$\operatorname{LGREEN}_{t}=\alpha_{0}+\alpha_{1} L E C_{t}+\alpha_{2} L G D P_{t}+u_{t}$

$L E C_{t}=\alpha_{0}+\alpha_{1} L_{G R E E N_{t}}+\alpha_{2} L G D P_{t}+u_{t}$

$L G D P_{t}=\alpha_{0}+\alpha_{1} L E C_{t}+\alpha_{2} L G R E E N_{t}+u_{t}$

The investigation is divided into two main parts. In the first part, we conduct the short-run causality tests, i.e. Granger causality test on detecting the directional relationship on these three variables. In the second part, we seek to examine the long-run relationship using linear and threshold (nonlinear) cointegration tests based on the relationship specified above. Unit-root tests are performed prior to the cointegration tests on checking the stationarity of the variables. The linear cointegration tests include Engle-Granger (EG) and PhillipsOuliaris (PO) while the threshold cointegration tests are based on the threshold autoregressive (TAR) and momentum threshold autoregressive (MTAR) models developed by Enders and Granger (1998) and Enders and Siklos (2001). The threshold cointegration tests are preferable to detect long-run relation in the presence of asymmetric adjustments in the error term. The linear cointegration assumes linearity adjustment in the error term hence has low power to detect asymmetric adjustment.

\subsection{Threshold cointegration- Enders-Siklos (ES) test}

In testing for asymmetric long-run relation in model (1), (2) and (3), the ES test is conducted based on Eq. 4:

$\Delta u_{t}=\rho_{1} u_{t-1}+\rho_{2}\left(1-I_{t}\right) u_{t-1}+\sum_{i=1}^{k} \delta_{i} \Delta u_{t-i}+v_{t}$ where $u_{t} i i d\left(0, \sigma^{2}\right)$ is the error term generated from the long-run relation in Eqs. 1 to 3, i.e.

$u_{t}=\operatorname{LGREEN}_{t}-\left[\alpha_{0}+\alpha_{1} L E C_{t}+\alpha_{2} L G D P_{t}\right]$

$u_{t}=L E C_{t}-\left[\alpha_{0}+\alpha_{1} L G R E E N_{t}+\alpha_{2} L G D P_{t}\right]$

$u_{t}=L G D P_{t}-\left[\alpha_{0}+\alpha_{1} L E C_{t}+\alpha_{2} L G R E E N_{t}\right]$

for Eqs. 1, 2 and 3 respectively; $\Delta u_{t}$ with $\mathrm{k}$ optimal lagged terms are included in Eq. 4 to correct for the disturbance terms so that there are uncorrelated disturbances; $I_{t}$ is the Heaviside indicator on defining the function of error tem:

$I_{t}=\left\{\begin{array}{lll}1 & \text { if } & u_{t-1} \geq \tau \\ 0 & \text { if } & u_{t-1}<\tau\end{array}\right.$

such that the error tem is adjusted by its lagged one value determined by the threshold value, $\tau$ under the threshold autoregressive (TAR) model. On the other hand, the function of error term is defined differently under the momentum threshold autoregressive (MTAR) model:

$I_{t}=\left\{\begin{array}{lll}1 & \text { if } & \Delta u_{t-1} \geq \tau \\ 0 & \text { if } & \Delta u_{t-1}<\tau\end{array}\right.$

According to Enders and Siklos (2001), MTAR specification is more appropriate if the error term exhibits the momentum in moving on one direction than the others.

$\rho_{1}$ and $\rho_{2}$ show the speed of adjustments on the deviations of the error term to converge to the longrun equilibrium level. The TAR and MTAR models permit restriction on $\rho_{1}$ and $\rho_{2}$ on testing for cointegration and asymmetric adjustment of error term based on Eq. 4:

(1) $H_{0}: \rho_{1}=\rho_{2}=0$ (no cointegration)

(2) $H_{0}: \rho_{1}=\rho_{2}$ (symmetric adjustment)

The hypothesis for cointegration is applicable using F-statistics based on the critical values tabulated by Enders and Siklos (2001). By rejecting the null hypothesis (1), we confirm the detection of long-run relation in Eqs. 1, 2 or 3. After detecting the long-run relation, one may proceed with hypothesis for asymmetric adjustment. The rejection of null hypothesis (2) indicates to the presence of asymmetric adjustment.

\section{Results}

\subsection{Short-run causality}

Table 1 summarizes the results of Granger causality test. This test seeks to reveal the directional relation between pairs of variables in the short-run basis. The null hypothesis is 'variable $A$ does not Granger cause variable B'. Therefore, the rejection of the null hypothesis indicates to the causal effect from variable A on variable B. From Table 1, we observe bi-directional relationship 
between LGDP and LEC but a one-way causal effect from LGDP to LEC in the short-run.

Table 1: Granger causality test

\begin{tabular}{|c|c|}
\hline Hypothesis & F-stat \\
\hline LGDP ${ }^{\gtrless}$ LEC & $5.9081^{* * *}$ \\
\hline LEC $\succ_{\text {LGDP }}$ & 2.1722 \\
\hline LGREEN $\succ_{\text {LEC }}$ & $3.3899 * *$ \\
\hline LEC $\succ_{\text {LGREEN }}$ & $7.1220^{* * *}$ \\
\hline LGREEN $\succ_{\text {LGDP }}$ & 1.5139 \\
\hline LGDP $\succ_{\text {LGREEN }}$ & 2.2142 \\
\hline
\end{tabular}

\subsection{Long-run relation}

Table 2 shows the results on unit-root tests using Augmented Dicky-Fuller (ADF) and KwiatkowskiPhillips-Schmidt-Shin (KPSS) tests. The null hypothesis for ADF test is the variable has unit-root (non-stationary) while the null hypothesis under KPSS stated that the variable is stationary. So the rejection of null hypothesis for ADF test indicates to the stationary while that for KPSS is not stationary. Both tests show that all variables are not stationary at levels but stationary at first differenced. The results imply that all variables are integrated of order 1, I (1). Since all variable are integrated with the same order, one can proceed to test for cointegration test on the long-run relationship stated in model (1) to (3).

Table 2: Unit-root tests

\begin{tabular}{ccccc}
\hline Variable & \multicolumn{2}{c}{ ADF } & \multicolumn{2}{c}{ PP } \\
\hline & Level & 1st diff & Level & 1st diff \\
LEC & -0.3361 & $-3.3210^{* *}$ & $0.8216^{* * *}$ & 0.1468 \\
LGDP & -0.1481 & $-6.0961^{* * *}$ & $0.2059^{* *}$ & 0.1006 \\
LGREEN & -1.5956 & $-3.8491^{* *}$ & $0.1468^{* *}$ & 0.0743 \\
\hline
\end{tabular}

Table 3 shows the results of linear cointegration tests (EG and PO). Both tests based on the null hypothesis of no cointegration by assuming symmetric adjustment in the error term. Both tests have detected evidences on the long-run relation in Model (1) and Model (2) but not in Model (3). Since linear cointegration test has low power in detecting the long-run relation in the presence of asymmetric adjustment in error term, we also provide results on threshold cointegration tests based on TAR and MTAR models (Table 4). The results reveal no longrun relation in all cases except one long-run relation holds in Model (3) under MTAR specification. Testing for asymmetric adjustment, we reject the null hypothesis, indicating the presence of asymmetric adjustment in the error term in Model (3).

Table 3: Linear cointegration test

\begin{tabular}{|c|c|c|c|c|}
\hline \multirow{2}{*}{ Model } & \multicolumn{2}{|c|}{ Engle-Granger test } & \multicolumn{2}{|c|}{ Phillips-Ouliaris test } \\
\hline & tau-statistic & z-statistic & tau-statistic & z-statistic \\
\hline 1 & $-4.1033^{*}$ & -18.2424 & $-4.5480^{* *}$ & $-29.1858^{* *}$ \\
\hline 2 & $-4.6412^{* *}$ & -19.2892 & $-4.9787 * *$ & $-33.5118^{* * *}$ \\
\hline 3 & -2.0342 & -7.7578 & -2.3324 & -10.1755 \\
\hline
\end{tabular}

Table 4: Threshold cointegration tests

\begin{tabular}{|c|c|c|c|c|c|c|}
\hline Eq. & Model & $\tau$ & $\rho_{1}$ & $\rho_{2}$ & Cointegra $\rho_{1}=\rho_{2}=0$ 。 & Asym. $\rho_{1}=\rho_{2}$ \\
\hline \multirow{2}{*}{1} & TAR & -0.0334 & $-0.4150^{* * *}$ & $-0.2264^{*}$ & 4.4992 & 0.9600 \\
\hline & MTAR & -0.0196 & $-0.4138^{* *}$ & -0.0261 & 6.0995 & 3.5909 \\
\hline \multirow{2}{*}{2} & TAR & -0.0421 & $-0.2740^{* *}$ & -0.0209 & 2.8024 & 1.5719 \\
\hline & MTAR & -0.0120 & $-0.2947^{* *}$ & -0.0592 & 2.7821 & 1.5353 \\
\hline \multirow{2}{*}{3} & TAR & -0.2482 & $-0.2011^{*}$ & $-0.3879 * *$ & 4.3308 & 0.9236 \\
\hline & MTAR & -0.0266 & -0.0805 & $-0.5358^{* * *}$ & $8.9573^{*}$ & $8.5736^{* *}$ \\
\hline
\end{tabular}

Summing up the results of linear and threshold cointegration tests, it is concluded that there is symmetric long-run relation in Model (1) and Model (2) but asymmetric long-run relation in Model (3). The three variables have inter-causal long-run (permanent) effect on each other which may determine the outcome of each variable on economy.

\section{Conclusion}

We conduct empirical analyses on examining the dynamic inter-relationship among energy consumption, environmental degradation (greenhouse gases emissions) and economic growth (GDP) in China, a highly energy consumed and dependence country. Our main objective is to study the short-run and long-run directional relations and to reveal the dynamic behaviour of the relationship (symmetric versus asymmetric and temporary or permanent (short-run versus long-run) effects). The Granger causality test and the cointegration tests (linear and threshold) are performed. Our results reveal both short-run and long-run inter-causal relationship among these three variables. Energy consumption and environmental degradation exhibit bi-directional relation and there is a one-way causal effect from GDP to energy consumption in the shortrun. In the long-run basis, we reveal symmetric relation in models with greenhouse gases emissions and energy consumption as dependent variable respectively but results reveal an asymmetric relation in the model with GDP as dependent variable.

Since the three variables are causally affected each other, the policymaker should consider the impact of these factors in policy decision and 
economic planning. Pollution problem is a globally concerned issue that may be harmful to economic growth and environmental health. As extensive energy consumption may lead to larger environmental degradation problem, the economic planning should co-implement with the energy conservation policy to foster economic sustainable growth and also to safeguard environmental health.

\section{Acknowledgment}

This work is supported by the Research University grant (1001/PMATHS/811312).

\section{References}

Al Sayed ARM and Sek SK (2013). Environmental Kuznets curve: Evidences from developed and developing economies. Applied Mathematical Sciences, 7(22): 1081-1092.

Alege PO, Adediran OS, and Ogundipe AA (2016). Pollutant emissions, energy consumption and economic growth in Negeria: A multivariate granger casuality famework. International Journal of Energy Economics and Policy, 6(2): 202-207.

Alshehry AS and Belloumi M (2015). Energy consumption, carbon dioxide emissions and economic growth: The case of Saudi Arabia. Renewable and Sustainable Energy Reviews, 41: 237 247.

Ang JB (2008). Economic development, pollutant emissions and energy consumption in Malaysia. Journal of Policy Modeling, 30(2): 271-278.

Apergis N and Payne JE (2009). Energy consumption and economic growth: Evidence from the commonwealth of independent states. Energy Economics, 31 (5): 641-647.

Balin BE and Akan DM (2015). EKC hypothesis and the effect of innovation: A panel data analysis. Journal of Business, Economics and Finance, 4(1): 81-91.

Chindo S, Abdulrahim A, Waziri SI, Huong WM, and Ahmad AA (2015). Energy consumption, CO2 emissions and GDP in Nigeria. GeoJournal, 80(3): 315-322.

Enders W and Granger CWJ (1998). Unit-root tests and asymmetric adjustment with an example using the term structure of interest rates. Journal of Business and Economic Statistics, 16(3): 304-311.

Enders W and Siklos PL (2001). Cointegration and threshold adjustment. Journal of Business and Economic Statistcs, 19(2): 166-176.

Esteve V and Tamarit C (2012). Is there an environmental Kuznets curve for Spain? Fresh evidence from old data. Economic Modelling, 29(6): 2696-2703.

Fatai K, Oxley L, and Scrimgeour F (2002). Energy consumption and employment in New Zealand: Searching for causality. In the annual Conference of New Zealand Association of Economists, NZAE, Wellington, New Zealand.

Franklin RS and Ruth M (2012). Growing up and cleaning Up: The environmental Kuznets curve. Applied Geography, 32(1): 29 39.
Galeotti M and Lanza A (1999). Richer and cleaner? A study on carbon dioxide emissions in developing countries. Energy Policy, 27(10): 565-573.

Ghosh S (2002). Electricity consumption and economic growth in India. Energy Policy, 30(2): 125-129.

Grossman GM and Krueger AB (1991). Environmental impact of a North American free trade agreement. National Bureau of Economic Research, No. w3914, University of Cambridge, Cambridge, UK.

Grossman GM and Krueger AB (1995). Economic growth and the environment. The Quarterly Journal of Economics, 110(2): 353-377.

Halicioglu F (2009). An econometric study of CO2 emissions, energy consumption, income and foreign trade in Turkey. Energy Policy, 37(3): 1156-1164.

$\mathrm{Hu}$ JL and Lin $\mathrm{CH}$ (2008). Disaggregated energy consumption and GDP in Taiwan: A threshold co-integration analysis. Energy Economics, 30(5): 2342-2358.

Huang WM, Lee GW, and Wu CC (2008). GHG emissions, GDP growth and the Kyoto protocol: A revisit of environmental Kuznets curve hypothesis. Energy Policy, 36(1): 239-247.

Kraft J and Kraft A (1978). On the relationship between energy and GNP. Journal of Energy and Development, 3(2): 401-403.

Leggett JA (2011). China's greenhouse gas emissions and mitigation policies. Congressional Research Service, 20(3): 533-560.

Narayan PK and Smyth R (2005). Electricity consumption, employment and real income in Australia evidence from multivariate Granger causality tests. Energy Policy, 33(9): 1109-1116.

Odhiambo NM (2009). Electricity consumption and economic growth in South Africa: A trivariate causality test. Energy Economics, 31 (5): 635-640.

Ozturk I (2010). A literature survey on energy-growth nexus. Energy Policy. 38(1): 340-349.

Payne JE (2010). Survey of the international evidence on the causal relationship between energy consumption and growth. Journal of Economic Studies, 37(1): 53-95.

Soytas U and Sari R (2009). Energy consumption, economic growth, and carbon emissions: Challenges faced by an EU candidate member. Ecological Economics, 68(6): 1667-1675.

Tsurumi T and Managi S (2010). Decomposition of the environmental Kuznets curve: Scale, technique, and composition effects. Environmental Economics and Policy Studies, 11(1-4): 19-36.

Wang KM (2013). The relationship between carbon dioxide emissions and economic growth: Quantile panel-type analysis. Quality and Quantity, 47(3): 1337-1366.

Wolde ET, Mulugeta W, and Hussen MM (2016). Energy Consumption, Carbon Dioxide Emissions and Economic Growth in Ethiopia. Global Journal of Management and Business Research B: 16(2): 1-10.

Yoo SH (2005). Electricity consumption and economic growth: Evidence from Korea. Energy Policy, 33(12): 1627-1632.

Yuan JH, Kang JG, Zhao CH, and Hu ZG (2008). Energy consumption and economic growth: Evidence from China at both aggregated and disaggregated levels. Energy Economics, 30(6): 3077-3094 